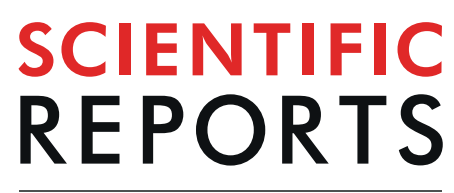

natureresearch

\title{
OPEN Predictors and their prognostic value for no ROSC and mortality after a non-cardiac surgery intraoperative cardiac arrest: a retrospective cohort study
}

\author{
Matheus F. Vane $\mathbb{1}^{1 *}$, Maria J. C. Carmona ${ }^{1}$, Sergio M. Pereira ${ }^{1,5}$, Karl B. Kern ${ }^{2}$, \\ Sérgio Timerman ${ }^{3}$, Guilherme Perez ${ }^{1}$, Luiz Antonio Vane ${ }^{4}$, Denise Aya Otsuki ${ }^{1}$ \& \\ José O. C. Auler Jr ${ }^{1}$
}

Data on predictors of intraoperative cardiac arrest (ICA) outcomes are scarce in the literature. This study analysed predictors of poor outcome and their prognostic value after an ICA. Clinical and laboratory data before and 24 hours ( $h$ ) after ICA were analysed as predictors for no return of spontaneous circulation (ROSC) and $24 \mathrm{~h}$ and 1-year mortality. Receiver operating characteristic curves for each predictor and sensitivity, specificity, positive and negative likelihood ratios, and post-test probability were calculated. A total of 167,574 anaesthetic procedures were performed, including 158 cases of ICAs. Based on the predictors for no ROSC, a threshold of 13 minutes of ICA yielded the highest area under curve (AUC) $(0.867[0.80-0.93])$, with a sensitivity and specificity of $78.4 \%[69.6-86.3 \%]$ and $89.3 \%[80.4-96.4 \%]$, respectively. For the 1-year mortality, the GCS without the verbal component $24 \mathrm{~h}$ after an ICA had the highest AUC (0.616 [0.792-0.956]), with a sensitivity of 79.3\% [65.5-93.1\%] and specificity of 86.1 [74.4-95.4]. ICA duration and GCS $24 \mathrm{~h}$ after the event had the best prognostic value for no ROSC and 1-year mortality. For $24 \mathrm{~h}$ mortality, no predictors had prognostic value.

Intraoperative cardiac arrest (ICA) is one of the most devastating events that can occur during anaesthesia. ICA has a wide range of incidence (1-44 cases/10,000 anaesthesia) and a mortality of over $70 \%{ }^{1-6}$.

Due to the high mortality associated with ICA, analysing predictors of poor outcomes are of great interest. The severity of organ dysfunction, cardiac arrest (CA) initial rhythm, use of epinephrine during cardiopulmonary resuscitation (CPR), previous neurological status, patient age, ICA duration, and the location of the hospital where the CA occurred have been linked to mortality ${ }^{7,8}$. In addition, only one study has evaluated laboratory data as a possible predictor of mortality. This study used the Physiological and Operative Severity Score for the enUmeration of Mortality and morbidity (POSSUM) and the Portsmouth predictor equation (P-POSSUM) to predict mortality in patients who had ICA ${ }^{9}$. However, the POSSUM includes only limited laboratory data and the study did not provide further evaluation, especially after the first 24 hours $(h)^{10,11}$. Finally, these studies have not evaluated how precise these factors are in predicting patient mortality.

Based on these premises, our aim was to investigate the predictors and their prognostic value for no return of spontaneous circulation (ROSC) and $24 \mathrm{~h}$ and 1-year mortality of patients who suffered ICA.

\footnotetext{
${ }^{1}$ Discipline of Anesthesiology (LIM-08), Hospital das Clinicas HCFMUSP, Faculdade de Medicina, Universidade de São Paulo, Sao Paulo, Brazil. ${ }^{2}$ Saver Heart Center, University of Arizona, Tucson, Arizona, USA. ${ }^{3}$ Heart Institute, Hospital das Clinicas HCFMUSP, Faculdade de Medicina, Universidade de São Paulo, Sao Paulo, Brazil. ${ }^{4}$ Faculty of Medical Sciences of Sao Jose dos Campos - HUMANITAS, São José dos Campos, Brazil. ${ }^{5}$ Divisao de Pneumologia, Instituto do Coracao, Hospital das Clinicas HCFMUSP, Faculdade de Medicina, Universidade de São Paulo, São Paulo, Brazil. *email: matheus.vane@hc.fm.usp.br
} 


\begin{abstract}
Methods
Inclusion and exclusion criteria. After obtaining approval from the Ethical Committee of the Clinics Hospital, Faculty of Medicine, University of Sao Paulo, Brazil ( $\left.\mathrm{N}^{\circ} 0822 / 06\right)$ and performing the research in accordance with the Declaration of Helsinki ${ }^{12}$, we retrospectively reviewed the medical records of patients who were subjected to anaesthetic procedures between 2007 and 2014. The Ethical Committee waived the need for informed written consent, since it was a retrospective study. All adult patients ( $>18$ years old) from the Central Institute of the Clinics Hospital of the University of Sao Paulo who suffered ICA were included in the analysis. ICA was defined as the absence of a central pulse associated with chest compressions for more than 10 seconds, as documented in patient medical records ${ }^{13,14}$. ROSC was defined as restoration of a spontaneous perfusing rhythm or arterial waveform for more than 20 minutes $^{15}$. The intraoperative period was defined as the time between the patient's entrance to the operating room (OR) and the patient's exit from the OR.

The study included all elective, urgent/emergent trauma and emergent/urgent non-trauma cases, except cardiac surgery cases. Patients excluded from the study were those who were deceased organ donors, who arrived at the OR in CA, whose medical records were unavailable, and who had had cardiac surgeries.
\end{abstract}

Analysed variables. The data were obtained from institutional patient medical records and from the laboratory system. The acquired parameters included data regarding patient status, surgery, laboratory exams and ICA (Table 1). Based on the unpredictability of the event, the data at admission, before CA, during CA, and immediately after ROSC were obtained from routine institutional records.

Outcomes (no ROSC, $24 \mathrm{~h}$ mortality and 1-year mortality). The patients were evaluated for no ROSC and $24 \mathrm{~h}$ and 1 -year mortality after the event. We contacted the patients after discharge by phone calls, emails, and text messages to account for mortality.

2.5 Statistical analysis. Data were collected and managed using REDCap electronic data capture software hosted at the institution ${ }^{16}$. Data were analysed by using the statistical software R 3.5.1 (R Foundation for Statistical Computing, Vienna, Austria) and RStudio (RStudio Team, Boston, MA). The library "pROC"17 was used for the ROC analysis in R. STATA (StataCorp LP, College Station, Texas, USA) software was also used to obtain the graphics for this paper.

Considering the high prevalence found in this study for each outcome, the authors estimated the prevalence ratio (PR) and its respective $95 \%$ confidence interval (95\% CI) from bivariate analysis based on the outcome of each variable. To perform the binomial analysis, continuous and discrete variables were categorized as presented in Table 1. From the binomial analysis, variables that had $p$ values lower than 0.20 were selected for multivariate analysis using Poisson regression with robust variance. The variable with the lowest $\mathrm{p}$ value from the bivariate analysis was first selected, and then, other variables with higher $p$ values were added to the analysis of the data. The authors retained the variables with $\mathrm{p}<0.05$ for the final model. Finally, the PR for the final model was estimated for each variable with its respective $95 \%$ CI.

After analysing the final model for each outcome, receiver operating characteristic curves (ROC) were generated for the predictors. The ROC curves were created using the bootstrap methodology (2000 samples). The areas under the ROC curves (AUCs) and confidence intervals calculated and were compared using the Delong and Clarke-Pearson method ${ }^{18}$. In addition, sensitivity, specificity and positive and negative likelihood ratios (LHR), along with their 95\%CI were calculated. The cut-off values were chosen according to the highest Youden index, calculated as (sensitivity + specificity -1). The AUC was considered non-discriminant if the 95\%CI included 0.5. For the ROC analysis of the GCS, the vocal response category was ignored to include patients who were awake and could follow commands but who were intubated or tracheostomized (i.e., a GCS of $10 \mathrm{~T}$ ). The curve with the highest AUC was selected and compared with the other ROC curves using DeLong's test for two correlated ROC curves. The two-step Fagan nomogram was used for post-test probability calculation ${ }^{19}$. Continuous variables were categorized according to the Youden index. The pre-test probability was estimated using the sample data. The significance level adopted by this study for all analyses was $\mathrm{p}<0.05$.

The survival curves for the 1-year mortality of patients who had ROSC were obtained by the Kaplan-Meier product-limit estimator.

\title{
Results
}

Sample characterization. There were 167,574 anaesthetic procedures (138,896 elective procedures and 28,678 urgent/emergent procedures), with 160 ICAs. Two patients (1.2\%) were transferred to another institution before $24 \mathrm{~h}$ after ROSC and were excluded from the analyses (Fig. 1).

The overall ICA prevalence was 9.54 cases/10,000 anaesthesia procedures, with 41.5 cases/10.000 anaesthesia procedures for urgent/emergent cases and 2.74/10.000 anaesthesia procedures for elective surgeries. Fifty-six patients did not achieve ROSC (case-fatality rate: 35.4\% [CI 28.0-43.4]). For those who achieved ROSC, 30 patients died within $24 \mathrm{~h}$ (case-fatality rate: $29.4 \%$ [CI 20.8-39.3]), and 73 patients died within one year (case-fatality rate: $71.6 \%$ [CI 61.8-80.1]) (Fig. 2). There were 38, 47, and 75 ICAs in elective, trauma and non-trauma patients, respectively.

The full data set is available in online supplement 1 . Most of the patients included in the study were men (57.6\%), with a median age of 53 [33-69.5] years and ASA-PS III (31.9\%) or I (26.9\%). Most of the ICA occurred during non-trauma emergency surgeries (46.1\%). The median length of ICA was 11 [4.0-22.3] minutes. All cases, except for one, occurred during general anaesthesia.

For elective surgeries, the most common cause of ICA was acute myocardial infarction (26.3\%). For trauma and non-trauma surgeries, the most common cause of ICA was hypovolemia (trauma: 80.9\%; non-trauma: 24\%). 


\begin{tabular}{|c|c|c|c|c|c|c|c|}
\hline & Patient and Surgery & OR admission* & Pre-CA intraoperative** & $\begin{array}{l}\text { Intraoperative } \\
\text { CA }\end{array}$ & $\begin{array}{l}\text { Immediately } \\
\text { after ROSC }\end{array}$ & \multirow{2}{*}{\multicolumn{2}{|c|}{$\begin{array}{l}\text { 24h after ROSC } C^{8 * *} \\
\text { Glasgow Coma Scale } \\
(\geq 14 \text { or } \geq 10 \mathrm{~T} \text { or }<14 \text { or } \\
\text { 10T) }\end{array}$}} \\
\hline \multirow[t]{5}{*}{ Clinical Data } & $\begin{array}{l}\text { Gender } \\
\text { (Male/Female) }\end{array}$ & $\begin{array}{l}\text { Presence of hypotension } \\
\text { (Yes or No) }\end{array}$ & $\begin{array}{l}\text { Vasoactive drug usage } \\
\text { (Yes or No) }\end{array}$ & Cause of CA & & & \\
\hline & $\begin{array}{l}\text { Age } \\
(<50 \text { or } \geq 50 \text { years })\end{array}$ & $\begin{array}{l}\text { Consciousness level } \\
\text { (Sedated or Awaked) }\end{array}$ & $\begin{array}{l}\text { Presence of arrhythmias } \\
\text { (Yes or No) }\end{array}$ & $\begin{array}{l}\text { Defibrillation } \\
\text { (Yes or No) }\end{array}$ & & & \\
\hline & $\begin{array}{l}\text { ASA-PS } \\
\text { (I, II, III, IV, or V) }\end{array}$ & & $\begin{array}{l}\text { Respiratory monitoring } \\
\text { changes (Yes or No) }\end{array}$ & $\begin{array}{l}\text { Initial Rhythm } \\
\text { (Shockable, } \\
\text { pulseless or } \\
\text { asystole) }\end{array}$ & & & \\
\hline & $\begin{array}{l}\text { Event Shift } \\
\text { (Daytime or Nightime) }\end{array}$ & & $\begin{array}{l}\text { Cardiovascular monitoring } \\
\text { changes (Yes or No) }\end{array}$ & $\begin{array}{l}\text { CA duration } \\
\text { (minutes) }\end{array}$ & & & \\
\hline & $\begin{array}{l}\text { Type of Surgery } \\
\text { (Elective, Trauma or Non-Trauma) }\end{array}$ & & & $\begin{array}{l}\text { Number of } \\
\text { epinephrine } \\
\text { doses }\end{array}$ & & & \\
\hline \multirow[t]{11}{*}{ Laboratorial Data } & & $\begin{array}{l}\text { PT/INR } \\
(<1.2)\end{array}$ & $\begin{array}{l}\text { Arterial pH } \\
(7.35-7.45)\end{array}$ & & $\begin{array}{l}\text { Arterial pH } \\
(7.35-7.45)\end{array}$ & $\begin{array}{l}\text { Arterial pH } \\
(7.35-7.45)\end{array}$ & $\begin{array}{l}\mathrm{PT} / \mathrm{INR} \\
(<1.2)\end{array}$ \\
\hline & & \begin{tabular}{|l} 
aTTP/R \\
$(<1.2)$
\end{tabular} & $\begin{array}{l}\text { Arterial Bicarbonate } \\
(22-26 \mathrm{mEq} / \mathrm{L})\end{array}$ & & \begin{tabular}{|l} 
Arterial \\
Bicarbonate \\
$(22-26$ \\
$\mathrm{mEq} / \mathrm{L})$ \\
\end{tabular} & $\begin{array}{l}\text { Arterial } \\
\text { Bicarbonate } \\
(22-26 \\
\mathrm{mEq} / \mathrm{L}) \\
\end{array}$ & $\begin{array}{l}\text { aTTP/R } \\
(<1.2)\end{array}$ \\
\hline & & $\begin{array}{l}\text { Platelet count } \\
(140-450,000 \text { platelets/ } \\
\left.\mathrm{mm}^{3}\right)\end{array}$ & $\begin{array}{l}\text { Arterial Base Excess } \\
(-3-+3)\end{array}$ & & $\begin{array}{l}\text { Arterial Base } \\
\text { Excess } \\
(-3-+3)\end{array}$ & $\begin{array}{l}\text { Arterial Base } \\
\text { Excess } \\
(-3-+3)\end{array}$ & \begin{tabular}{|l} 
Platelet \\
count \\
$(140-$ \\
450,000 \\
platelets/ \\
$\left.\mathrm{mm}^{3}\right)$ \\
\end{tabular} \\
\hline & & $\begin{array}{l}\text { Serum creatinine } \\
(<1.2 \mathrm{mg} / \mathrm{dL})\end{array}$ & $\begin{array}{l}\text { Sodium levels } \\
(135-145 \mathrm{mEq} / \mathrm{L})\end{array}$ & & \begin{tabular}{|l|} 
Sodium levels \\
$(135-145$ \\
$\mathrm{mEq} / \mathrm{L})$
\end{tabular} & $\begin{array}{l}\text { Sodium levels } \\
(135-145 \\
\mathrm{mEq} / \mathrm{L})\end{array}$ & \begin{tabular}{|l|}
$\begin{array}{l}\text { Serum } \\
\text { creatinine } \\
(<1.2)\end{array}$ \\
\end{tabular} \\
\hline & & $\begin{array}{l}\text { Serum Urea } \\
(10-50 \mathrm{mg} / \mathrm{dL}))\end{array}$ & $\begin{array}{l}\text { Potassium levels } \\
(3.5-5 \mathrm{mEq} / \mathrm{L})\end{array}$ & & \begin{tabular}{|l} 
Potassium \\
levels \\
$(3.5-5 \mathrm{mEq} / \mathrm{L})$
\end{tabular} & \begin{tabular}{|l} 
Potassium \\
levels \\
$(3.5-5 \mathrm{mEq} / \mathrm{L})$
\end{tabular} & \begin{tabular}{|l} 
Serum \\
Urea \\
$(10-50)$
\end{tabular} \\
\hline & & & $\begin{array}{l}\text { Chloride levels } \\
(98-107 \mathrm{mEq} / \mathrm{L})\end{array}$ & & $\begin{array}{l}\text { Chloride levels } \\
(98-107 \\
\mathrm{mEq} / \mathrm{L})\end{array}$ & $\begin{array}{l}\text { Chloride levels } \\
(98-107 \\
\mathrm{mEq} / \mathrm{L})\end{array}$ & \\
\hline & & & $\begin{array}{l}\text { Ionic calcium levels } \\
(4.4-5.4 \mathrm{mEq} / \mathrm{L})\end{array}$ & & $\begin{array}{l}\text { Ionic calcium } \\
\text { levels } \\
(4.4-5.4 \\
\mathrm{mEq} / \mathrm{L})\end{array}$ & $\begin{array}{l}\text { Ionic calcium } \\
\text { levels } \\
(4.4-5.4 \\
\mathrm{mEq} / \mathrm{L}) \\
\end{array}$ & \\
\hline & & & $\begin{array}{l}\text { Arterial Lactate } \\
(<14.4 \mathrm{mg} / \mathrm{dL})\end{array}$ & & $\begin{array}{l}\text { Arterial } \\
\text { Lactate } \\
(<14.4 \mathrm{mg} / \\
\mathrm{dL})\end{array}$ & $\begin{array}{l}\text { Arterial } \\
\text { Lactate } \\
(<14.4 \mathrm{mg} / \mathrm{dL})\end{array}$ & \\
\hline & & & $\begin{array}{l}\text { Glucose levels } \\
(70-100 \mathrm{mg} / \mathrm{dL})\end{array}$ & & $\begin{array}{l}\text { Glucose levels } \\
\text { (70-100 mg/ } \\
\mathrm{dL})\end{array}$ & $\begin{array}{l}\text { Glucose levels } \\
\text { Glucose levels } \\
(70-100 \mathrm{mg} / \\
\mathrm{dL})\end{array}$ & \\
\hline & & & $\begin{array}{l}\text { Hemoglobin } \\
(12-16 \mathrm{~g} / \mathrm{dL})\end{array}$ & & $\begin{array}{l}\text { Hemoglobin } \\
(12-16 \mathrm{~g} / \mathrm{dL})\end{array}$ & $\begin{array}{l}\text { Hemoglobin } \\
(12-16 \mathrm{~g} / \mathrm{dL})\end{array}$ & \\
\hline & & & $\begin{array}{l}\text { Hematocrit } \\
(35-47 \%)\end{array}$ & & $\begin{array}{l}\text { Hematocrit } \\
(35-47 \%)\end{array}$ & $\begin{array}{l}\text { Hematocrit } \\
(35-47 \%)\end{array}$ & \\
\hline
\end{tabular}

Table 1. Acquired parameters. Variable categorization in parenthesis. aTTP/R: normalized ratio of activated partial thromboplastin time; ASA-PS: American Society of Anesthesiologists Physical Statuts Classification; PT/INR: international normalized ratio of prothrombin time; ROSC: Return of spontaneous circulation. *Tolerance: $24 \mathrm{~h}$ for elective cases and $6 \mathrm{~h}$ for urgent/emergent cases; **Tolerance: Clinical data: 60 min before CA; Laboratorial data: 120 minutes before CA; \& *Tolerance: 60 min \& **Tolerance: 6 h. Hypotension: Systolic Arterial Pressure $<90 \mathrm{mmHg}$ or mean arterial pressure $<50 \mathrm{mmHg}$; Arrhythmias: Any new ECG findings or rhythm changes; Respiratory Monitoring Changes: new findings on oximetry, capnography, airway pressure, or tidal volume; Cardiovascular Monitoring Changes: new findings on heart rate or blood pressure.

All patients who survived for more than one year were neurologically intact with a GCS of 15, except for one patient who continued to be tracheostomized and had a GCS of $10 \mathrm{~T}$.

Predictors for no ROSC, $24 \mathrm{~h}$ mortality and 1-year mortality. The predictors for the analysed endpoints are shown in Table 2. The predictors for no ROSC were hypovolemia as the cause of ICA (adjusted PR 2.42 [CI 1.52-3.86], $\mathrm{p}<0.001$ ), hypotension at OR admission (adjusted PR 1.60 [CI 1.07-2.40], $\mathrm{p}=0.02$ ) and ICA duration (adjusted PR 1.03 [CI 1.02-1.04], p $<0.001$ ).

Regarding $24 \mathrm{~h}$ mortality, hypovolemia as the cause of ICA (adjusted PR 4.15 [95\% CI 1.98-8.68], p $<0.001$ ), sodium greater than $145 \mathrm{mEq} / \mathrm{L}$ or less than $135 \mathrm{mEq} / \mathrm{L}$ at admission (adjusted PR 2.37 [CI 1.23-4.58], $\mathrm{p}=0.010$ ), PT/INR greater than 1.2 at admission (adjusted PR 2.43 [CI 1.24-4.75], $\mathrm{p}=0.010$ ), and duration of ICA (per minute) (adjusted PR 1.04 [CI 1.03-1.06], $\mathrm{p}<0.001$ ) were the predictors. 


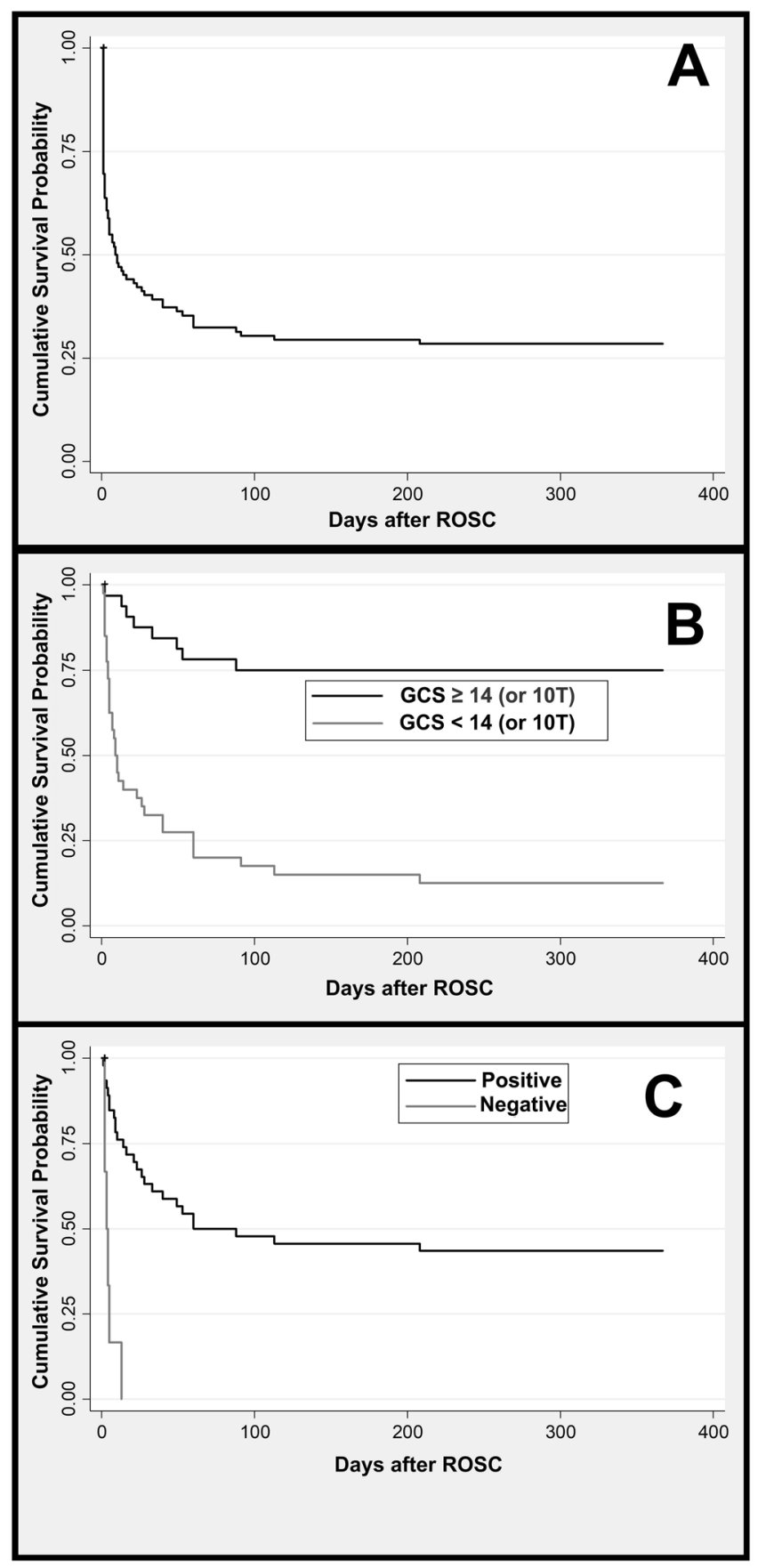

Figure 1. Study flowgram diagram.

The multivariate model analysis showed that the 1-year mortality was independently associated with GCS $<14$ (or $10 \mathrm{~T}$ for intubated patients) $24 \mathrm{~h}$ after ROSC (adjusted PR 2.70 [95\% CI 1.52-4.79], $\mathrm{p}=0.001$ ), a decrease in the PT/INR during the first $24 \mathrm{~h}$ (adjusted PR 1.66 [95\% CI 1.11-2.47], $\mathrm{p}=0.013$ ), and the ICA duration (adjusted PR 1.01 [95\% CI 1.01-1.04], $\mathrm{p}=0.048$ ) (Fig. 2).

ROC analysis of the predictors. The specificity, sensitivity, area under curve (AUC) and thresholds for each predictor of mortality are shown in Table 3. The LHR and post-test probabilities are shown in Table 4 . Based on the independent risk factors for no ROSC, a threshold of 13 minutes of ICA yielded a significantly higher AUC than the other independent risk factors $(0.867$ vs 0.737 vs $0.610, \mathrm{p}=0.04, \mathrm{p}<0.001)$, with a sensitivity and specificity of $78.4 \%$ [69.6-86.3\%] and 89.3 [80.4-93.3\%], respectively.

For the $24 \mathrm{~h}$ mortality, no predictors were associated with prognosis.

GCS without a vocal response $24 \mathrm{~h}$ after ROSC, CA duration and PT/INR variation between admission and the first $24 \mathrm{~h}$ after ROSC were associated with 1-year mortality. GCS without a vocal response had the highest 


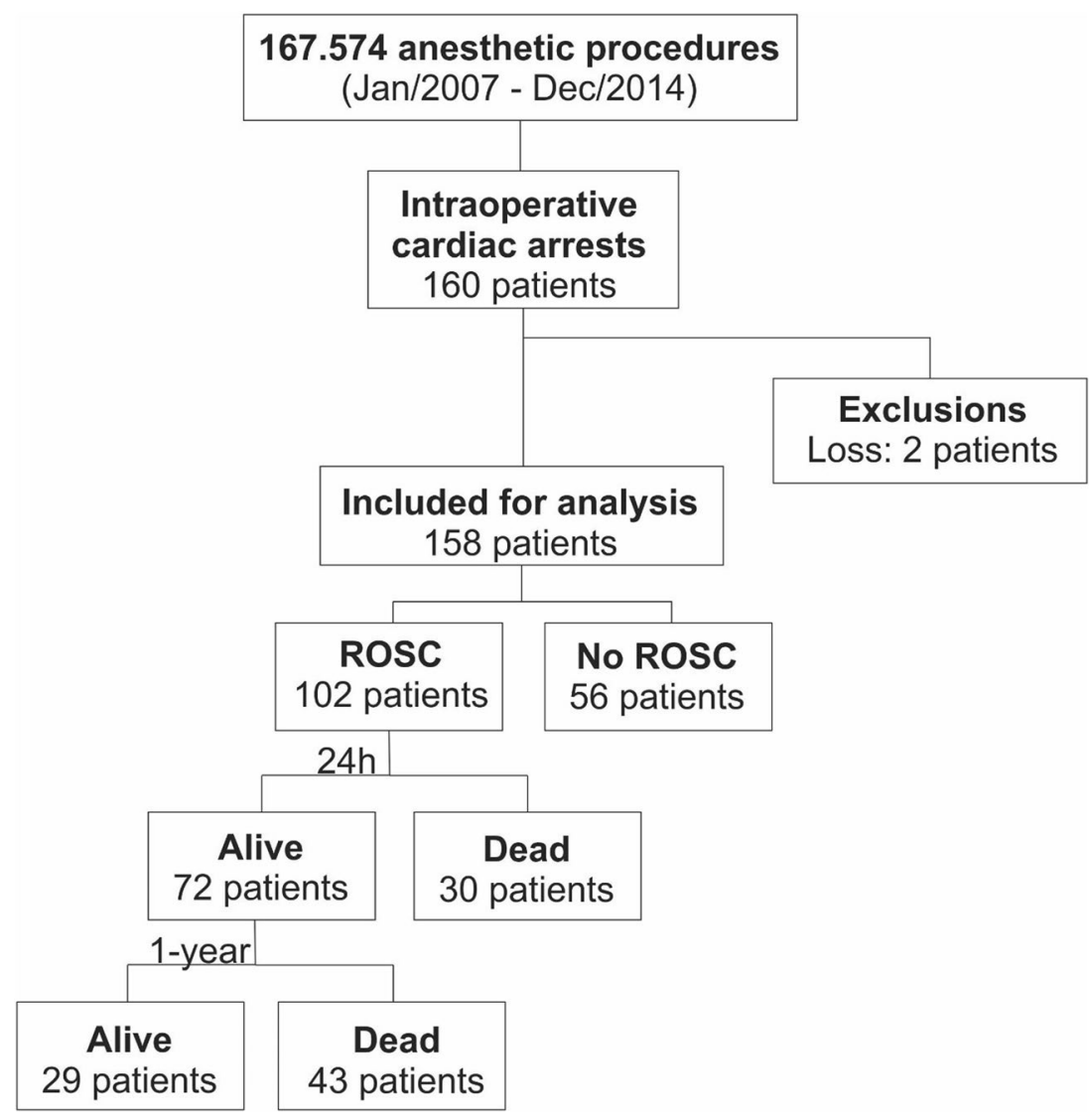

Figure 2. Plots of Kaplan-Meier product limit estimates of survival after ICA. (A): for patients with intraoperative cardiac arrest; (B): According to the INR/PT variation; (C): according to GCS $24 \mathrm{~h}$ after the event. + : Censoring of two cases who were lost to follow-up.

\begin{tabular}{|c|c|c|c|c|}
\hline Predictors & $\mathbf{P R}_{\mathrm{w}}$ & $\mathbf{P R}_{\text {adj }}$ & CI 95\% $\left(\mathrm{PR}_{\text {adj }}\right)$ & $p$ \\
\hline \multicolumn{5}{|l|}{ No ROSC } \\
\hline Hypovolemia as the Cause of $C A$ & 3.36 & 2.42 & $1.52-3.86$ & $<0.001$ \\
\hline Hypotension at OR admission & 1.85 & 1.60 & $1.07-2.40$ & 0.022 \\
\hline CA duration (per minute) & 1.03 & 1.03 & $1.02-1.04$ & $<0.001$ \\
\hline \multicolumn{5}{|l|}{$24 \mathrm{~h}$ Mortality } \\
\hline Hypovolemia as the Cause of $C A$ & 3.01 & 4.15 & $1.98-8.68$ & $<0.001$ \\
\hline $\mathrm{Na}<135$ or $>145 \mathrm{mEq} / \mathrm{L}$ before $\mathrm{CA}$ & 2.16 & 2.37 & $1.23-4.58$ & 0.010 \\
\hline$P T / I N R>1.2$ at admission & 2.71 & 2.43 & $1.24-4.75$ & 0.010 \\
\hline CA duration (per minute) & 1.03 & 1.04 & $1.03-1.06$ & $<0.001$ \\
\hline \multicolumn{5}{|l|}{ 1-year Mortality } \\
\hline Glasgow Coma Scale 24 after $R O S C<14$ ou $<10 \mathrm{~T}$ & 3.50 & 2.70 & $1.52-4.79$ & 0.001 \\
\hline Negative PT/INR variation between admission and the first $24 \mathrm{~h}$ after ROSC & 1.29 & 1.66 & $1.11-2.47$ & 0.013 \\
\hline CA duration (per minute) & 1.01 & 1.01 & $1.01-1.04$ & 0.048 \\
\hline
\end{tabular}

Table 2. Predictors for mortality. CA: Cardiac arrest; 95\% CI: 95\% Confidence interval; PT/INR: international normalized ratio of prothrombin time; $\mathrm{PR}_{\mathrm{aj}}$ : Adjusted prevalence ratio; $\mathrm{PR}_{\mathrm{r}}$ : Raw prevalence ratio.

AUC, with a sensitivity of 79.3\% [65.5-93.1\%] and specificity of 86.1 [74.4-95.4]. GCS without a vocal response $24 \mathrm{~h}$ after ROSC had a significantly higher AUC than PT/INR variation $(0.874$ vs 0.594 , respectively, $\mathrm{p}=<0.001)$.

\section{Discussion}

The main findings of this study were that based on the predictors for no ROSC, a threshold of 13 minutes of ICA yielded a significantly higher AUC than the other predictors. For the $24 \mathrm{~h}$ mortality, no predictors had prognostic value. For the 1-year mortality, the GCS $24 \mathrm{~h}$ after ICA had the highest AUC.

The ICA duration was independently associated with no ROSC and 1-year mortality and had lower cut-offs for longer survival. Ray et al. proposed that good diagnostic value of a biomarker would have an accuracy of 


\begin{tabular}{|c|c|c|c|c|c|c|c|c|}
\hline & \multicolumn{2}{|c|}{ Sensitivity } & \multicolumn{2}{|c|}{ Specificity } & \multicolumn{2}{|l|}{ AUC } & \multirow[t]{2}{*}{ Threshold } & \multirow[t]{2}{*}{ p-AUC } \\
\hline & $\%$ & $95 \% C I$ & $\%$ & $95 \% C I$ & & $95 \% C I$ & & \\
\hline \multicolumn{9}{|l|}{ No-ROSC } \\
\hline CA duration (minutes) & 78.43 & 69.61-86.27 & 89.29 & $80.36-96.43$ & 0.8665 & $0.8004-0.9328$ & 13.5 & - \\
\hline Cause of $C A$ & 77.50 & 68.63-85.29 & 67.90 & $55.36-80.36$ & 0.7265 & $0.6526-0.8005$ & Hypovolemia & 0.004 \\
\hline $\begin{array}{l}\text { Hypotension at } O R \\
\text { admission }\end{array}$ & 77.50 & $68.63-85.29$ & 44.60 & $32.14-57.14$ & 0.6104 & $0.5332-0.6878$ & Presence & $<0.001$ \\
\hline \multicolumn{9}{|l|}{ 24h Mortality } \\
\hline CA duration (minutes) & 61.64 & $50.68-72.60$ & 56.67 & $40.00-73.30$ & 0.6159 & $0.4997-0.7323$ & 10 & - \\
\hline Cause of $C A$ & 73.97 & 64.38-83.56 & 46.67 & $30.00-63.33$ & 0.6032 & $0.4993-0.7072$ & Hypovolemia & 0.882 \\
\hline $\begin{array}{l}\text { Sodium levels before } C A \\
(m E q / L)\end{array}$ & 68.25 & $57.14-79.37$ & 43.48 & $26.09-65.22$ & 0.5310 & $0.3824-0.6797$ & 136 & 0.374 \\
\hline PT/INR at admission & 58.18 & $45.45-70.91$ & 28.57 & $9.52-47.62$ & 0.5662 & $0.3149-0.5526$ & $>1.2$ & 0.617 \\
\hline \multicolumn{9}{|l|}{ 1-year Mortality } \\
\hline $\begin{array}{l}\text { Glasgow Coma Scale } 24 \\
\text { after ROSC }\end{array}$ & 79.31 & $65.52-93.10$ & 86.05 & $74.42-95.35$ & 0.8737 & $0.7918-0.9556$ & $9 *$ & - \\
\hline CA duration (minutes) & 64.38 & $53.42-75.34$ & 79.31 & $65.52-93.10$ & 0.7503 & $0.6482-0.8525$ & 5.5 & 0.066 \\
\hline $\begin{array}{l}\text { PT/INR variation } \\
\text { between admission and } \\
\text { the first } 24 \mathrm{~h} \text { after } R O S C\end{array}$ & 18.75 & $6.25-34.38$ & 1 & 1 & 0.5937 & $0.5251-0.6624$ & Negative & $<0.001$ \\
\hline
\end{tabular}

Table 3. Sensitivity, specificity and area under curve (AUC) for the predictors. *Glasgow Coma Scale with supression of best vocal response. Legend: CA: Cardiac arrest; 95\% CI: 95\% Confidence interval; OR: operating room; PT/INR: international normalized ratio of prothrombin time; ROSC: return of spontaneous circulation; p-AUC: vs the highest ROC AUC.

\begin{tabular}{|c|c|c|c|c|c|c|c|c|}
\hline & LHR+ & 95\%CI & $\begin{array}{l}\text { Post-test } \\
\text { Probability }\end{array}$ & $95 \% \mathrm{CI}$ & LHR- & $95 \% \mathrm{CI}$ & $\begin{array}{l}\text { Post-test } \\
\text { Probability }\end{array}$ & 95\% CI \\
\hline \multicolumn{9}{|l|}{ No-ROSC } \\
\hline CA duration (minutes) & 7.32 & $3.41-16$ & $93 \%$ & $86-97 \%$ & 0.24 & $0.17-0.35$ & $30 \%$ & $24-39 \%$ \\
\hline Cause of CA & 2.41 & $1.62-3.58$ & $81 \%$ & $75-87 \%$ & 0.33 & $0.22-0.50$ & $38 \%$ & $29-48 \%$ \\
\hline $\begin{array}{l}\text { Hypotension at OR } \\
\text { admission }\end{array}$ & 1.40 & $1.08-1.81$ & $72 \%$ & $66-77 \%$ & 0.51 & $0.32-0.80$ & $48 \%$ & $37-59 \%$ \\
\hline \multicolumn{9}{|l|}{ 24h Mortality } \\
\hline CA duration (minutes) & 1.42 & $0.91-2.23$ & $78 \%$ & $69-84 \%$ & 0.68 & $0.44-1.04$ & $62 \%$ & $52-72 \%$ \\
\hline Cause of CA & 1.39 & $0.97-1.99$ & $77 \%$ & $70-83 \%$ & 0.56 & $0.32-0.96$ & $58 \%$ & $44-70 \%$ \\
\hline $\begin{array}{l}\text { Sodium levels before } C A \\
(m E q / L)\end{array}$ & 1.18 & $0.79-1.76$ & $76 \%$ & $68-83 \%$ & 0.77 & $0.43-1.37$ & $68 \%$ & $54-79 \%$ \\
\hline PT/INR at admission & 0.81 & $0.57-1.16$ & $68 \%$ & $60-75 \%$ & 1.46 & $0.7-3.08$ & $79 \%$ & $65-89 \%$ \\
\hline \multicolumn{9}{|l|}{ 1-Year Mortality } \\
\hline $\begin{array}{l}\text { Glasgow Coma Scale } 24 \\
\text { after ROSC** }\end{array}$ & 6.82 & $2.93-16$ & $82 \%$ & $66-92 \%$ & 0.23 & $0.11-0.48$ & $13 \%$ & $7-24 \%$ \\
\hline CA duration (minutes) & 3.11 & $1.5-6.48$ & $89 \%$ & $79-94 \%$ & 0.45 & $0.31-0.64$ & $53 \%$ & $44-62 \%$ \\
\hline \begin{tabular}{|l|} 
PT/INR variation \\
between admission and \\
the first $24 \mathrm{~h}$ after ROSC
\end{tabular} & Inf & $0.49-139$ & $100 \%$ & $44-100 \%$ & 0.81 & $0.69-0.99$ & $56 \%$ & $52-61 \%$ \\
\hline
\end{tabular}

Table 4. Positive and Negative Likelihood ratios ( + LHR, - LHR), post-tests probability for the analyzed thresholds. *Glasgow Coma Scale with supression of best vocal response. Legend: CA: Cardiac arrest; 95\% CI: 95\% Confidence interval; OR: operating room; PT/INR: international normalized ratio of prothrombin time; ROSC: return of spontaneous circulation.

0.75-0.90, a +LHR between 5 and 10, a -LHR between 0.1 and 0.2 and an AUC between 0.75 and $0.90^{20}$. An ICA duration of greater than 13 minutes predicted no ROSC. This means that if an ICA lasts for more than 13 minutes, there is a $93 \%$ probability that this patient will not achieve ROSC. Of note, the ICA duration had a direct association with the degree of hypoxia, which is predictor of poor outcome following out-of-hospital $\mathrm{CA}^{21,22}$. In animal studies, the average time of anoxia associated with irreversible neurologic damage is between 4 and $10 \mathrm{~min}$ utes $^{23,24}$. However, in humans, when effective CPR is present, the CA duration can be more than 17 minutes, while still having a good neurological outcome ${ }^{21}$. One out-of-hospital CA study considered only a CA duration of greater than 25 minutes as a risk of death ${ }^{22}$. In contrast to previous findings, in the 1-year mortality analysis, an ICA duration of 5.5 minutes had the greatest AUC for sensitivity and specificity and wasassociated with a higher probability of death and an even lower ICA duration than previous studies ${ }^{21,22}$. This finding was supported by the fact that in patients who achieved ROSC, there was a $1 \%$ increase in the patient's likelihood of death for each minute of CA according to the 1-year mortality. 
Several studies linked the cause of ICA to a prognostic factor ${ }^{25-28}$. In our study, only hypovolemia as a cause of ICA was independently associated only with no ROSC. This is in accordance with previous studies on the association of the number of transfused units, the amount of intraoperative bleeding and hypovolemia with in-hospital mortality ${ }^{26-28}$. In addition, these studies showed that the cause of ICA was no longer associated with 30-day mortality, which is in accordance with our findings. One may assume that after the first $24 \mathrm{~h}$, hypovolemia is most likely resolved, and organ damage (ischaemia-reperfusion injury) is mainly associated with the outcome. Furthermore, the fact that the ICA duration has a better prognostic value than the cause of ICA for mortality might suggest that organ damage is more time-dependent than aetiology-dependent.

The use of GCS after CA has been linked to neurological prognosis. The higher the GCS is $24 \mathrm{~h}$ after CA, the better the neurological outcome ${ }^{29,30}$. It is estimated that $80 \%$ of patients will be comatose after $\mathrm{CA}^{31}$. Within $24 \mathrm{~h}$, more than $95 \%$ of patients who recover consciousness will awake ${ }^{31}$. Within $48 \mathrm{~h}$, if targeted temperature management is present, $78 \%$ of patients who recover consciousness will awake ${ }^{32}$. We found that GCS without a verbal response $24 \mathrm{~h}$ after the event was a predictor of 1 -year mortality, with a good AUC, a high + LHR and a low -LHR, yielding a positive post-test probability of $82 \%$ and a negative post-test probability of $13 \%$. Hence, we can assume that if the value of the GCS is lower than 15 or $10 \mathrm{~T}$ after $24 \mathrm{~h}$, there is an $82 \%$ probability of 1 -year mortality for the patient. Thus, this variable can be classified as having good prognostic value for mortality ${ }^{20}$. Eventually, since all patients who survived for one year had a GCS of 15 or $10 \mathrm{~T}$, we could also infer that these conclusions, drawn for mortality, could be extrapolated for neurological outcomes.

To the best of our knowledge, this is the first study to evaluate laboratory and clinical data at admission, immediately before ICA, immediately after ROSC, and $24 \mathrm{~h}$ after ROSC. This study was also the first to analyse the association of changes in laboratory data during the first $24 \mathrm{~h}$ with the 1 -year mortality and to include a sensitivity and specificity analysis of each of these variables.

Regarding laboratory data, PT/INR at admission was independently associated with a greater risk of death within $24 \mathrm{~h}$ and its increase in the first $24 \mathrm{~h}$ was associated with 1-year mortality. In this manner, we could presume that PT/INR should be analysed as a static and dynamic variable. During acidosis, hypothermia, and/or haemodilution, which are common situations for patients experiencing or recovering from $\mathrm{CA}$, the coagulation system is greatly affected, resulting in hypocoagulation ${ }^{33}$. Recently, hypocoagulation has been attributed to tissue hypoperfusion, with a direct association between the degree of hypoperfusion and the intensity of changes in the coagulation system ${ }^{34}$. In a previous study, base excess levels lower than -6 were associated with increased PT and aTTP, reinforcing the theory that hypoperfusion can generate coagulopathy ${ }^{35}$. In this study, most of the patients had base excess lower than -6 , either before or after the event, which is a possible explanation for the increase in PT/INR. Although the PT/INR variation had a high specificity and an infinite + LHR for 1-year mortality, the sensitivity was low, resulting in a small AUC and low -LHR. Lactate, which is another marker of hypoperfusion, did not correlate with the outcomes. This might be because most of the analysed patients $(95.6 \%)$ had high lactate levels after CA and no patient with normal lactate levels died.

Finally, a surprising result of our study is that, contrary to previous studies, the ASA-PS and the comorbidities were neither independently associated nor had any prognostic value with any of the analysed outcomes. The inclusion of trauma patients, who were mostly ASA-PS I and II, might explain this lack of association ${ }^{2,25,36,37}$. The high number of trauma patients might have biased the analysis of ASA-PS as a predictor.

Limitations. This study had some limitations. First, we pooled and compared all surgeries - elective, urgent and emergent. This was done due to the low prevalence of ICA, especially in elective surgeries. Thus, the sample in this study consisted of more urgent and emergent surgeries than elective surgeries. This fact, however, allowed greater external validity of the study, especially for tertiary academic hospitals, where there is a mixture of elective, urgent and emergent surgeries. In addition, we could not differentiate between the total number of procedures performed for trauma and non-trauma surgeries due to the lack of an electronic medical record. Second, this was a single-centred study performed at a tertiary academic hospital where the patients are clinically more severe, which might have increased the risk of death. The advantage of using a single centred is that one can assume standardized patient care, including the management of CPR. Third, this was a retrospective study based on patients' charts. There might be some record bias that we were not aware of. Some anaesthesiologists might have underestimated the duration of the ICA, while others might have misdiagnosed the cause or the electrical rhythm. Fourth, another important limitation is the decision to continue resuscitative efforts during cardiac arrest. A longer ICA duration (especially if longer than 20 minutes) is more prone to termination of resuscitative efforts $^{38}$. In our retrospective study, the treating clinicians were not blinded to the ICA duration at the time of the ICA, and the predictive estimates may be artificially inflated.

Although we had some loss of follow-up, it was very low. Most of the patients either died during hospitalization or continued to visit the hospital for routine follow-up, the loss to follow-up was limited. In addition, institutional electronic system can log every time the patient comes for a consultation, allowing the authors to check for survival. Finally, we acknowledge the limitations caused by the wide confidence intervals of some of the analyses, the large number of factors analysed and thepoor calibration and discrimination of some models.

\section{Conclusion}

ICA duration and GCS $24 \mathrm{~h}$ after the event had the best prognostic value for ROSC and 1-year mortality. For $24 \mathrm{~h}$ mortality, no predictors had prognostic value. Larger, multicentred studies should be performed to validate these findings.

Received: 10 July 2019; Accepted: 1 October 2019;

Published online: 18 October 2019 


\section{References}

1. Kawashima, Y. et al. Anesthesia-related mortality and morbidity over a 5-year period in 2,363,038 patients in Japan. Acta anaesthesiologica Scandinavica 47, 809-817 (2003).

2. Olsson, G. L. \& Hallen, B. Cardiac arrest during anaesthesia. A computer-aided study in 250,543 anaesthetics. Acta anaesthesiologica Scandinavica 32, 653-664 (1988).

3. Chopra, V., Bovill, J. G. \& Spierdijk, J. Accidents, near accidents and complications during anaesthesia. A retrospective analysis of a 10-year period in a teaching hospital. Anaesthesia 45, 3-6 (1990).

4. Kazaure, H. S., Roman, S. A., Rosenthal, R. A. \& Sosa, J. A. Cardiac arrest among surgical patients: an analysis of incidence, patient characteristics, and outcomes in ACS-NSQIP. JAMA surgery 148, 14-21, https://doi.org/10.1001/jamasurg.2013.671 (2013).

5. Boonmak, P. et al. Surveillance of anesthetic related complications at Srinagarind Hospital, Khon Kaen University, Thailand. Journal of the Medical Association of Thailand = Chotmaihet thangphaet 88, 613-622 (2005).

6. Ruiz Neto, P. P. \& Amaral, R. V. G. Cardiac arrest during anesthesia in a multicenter hospital: a descriptive study Rev. bras. Anestesiol 36, 149-158 (1986).

7. Ramachandran, S. K. et al. Predictors of survival from perioperative cardiopulmonary arrests: a retrospective analysis of 2,524 events from the Get With The Guidelines-Resuscitation registry. Anesthesiology 119, 1322-1339, https://doi.org/10.1097/ ALN.0b013e318289bafe (2013).

8. Constant, A. L. et al. Predictors of functional outcome after intraoperative cardiac arrest. Anesthesiology 121, 482-491, https://doi. org/10.1097/ALN.0000000000000313 (2014).

9. Kim, S. H., Kil, H. K., Kim, H. J. \& Koo, B. N. Risk Assessment of Mortality Following Intraoperative Cardiac Arrest Using POSsUM and P-POSSUM in Adults Undergoing Non-Cardiac Surgery. Yonsei medical journal 56, 1401-1407, https://doi.org/10.3349/ ymj.2015.56.5.1401 (2015).

10. Copeland, G. P., Jones, D. \& Walters, M. POSSUM: a scoring system for surgical audit. Br J Surg 78, 355-360 (1991).

11. Whiteley, M. S., Prytherch, D. R., Higgins, B., Weaver, P. C. \& Prout, W. G. An evaluation of the POSSUM surgical scoring system. Br J Surg 83, 812-815 (1996).

12. World Medical, A. World Medical Association Declaration of Helsinki: ethical principles for medical research involving human subjects. JAMA 310, 2191-2194, https://doi.org/10.1001/jama.2013.281053 (2013).

13. Kleinman, M. E. et al. 2017 American Heart Association Focused Update on Adult Basic Life Support and Cardiopulmonary Resuscitation Quality: An Update to the American Heart Association Guidelines for Cardiopulmonary Resuscitation and Emergency Cardiovascular Care. Circulation 137, e7-e13, https://doi.org/10.1161/CIR.0000000000000539 (2018).

14. Kleinman, M. E. et al. Part 5: Adult Basic Life Support and Cardiopulmonary Resuscitation Quality: 2015 American Heart Association Guidelines Update for Cardiopulmonary Resuscitation and Emergency Cardiovascular Care. Circulation 132, S414-435, https://doi.org/10.1161/CIR.0000000000000259 (2015).

15. Jacobs, I. et al. Cardiac arrest and cardiopulmonary resuscitation outcome reports: update and simplification of the Utstein templates for resuscitation registries. A statement for healthcare professionals from a task force of the international liaison committee on resuscitation (American Heart Association, European Resuscitation Council, Australian Resuscitation Council, New Zealand Resuscitation Council, Heart and Stroke Foundation of Canada, InterAmerican Heart Foundation, Resuscitation Council of Southern Africa). Resuscitation 63, 233-249, https://doi.org/10.1016/j.resuscitation.2004.09.008 (2004).

16. Harris, P. A. et al. Research electronic data capture (REDCap)-a metadata-driven methodology and workflow process for providing translational research informatics support. J Biomed Inform 42, 377-381, https://doi.org/10.1016/j.jbi.2008.08.010 (2009).

17. Robin, X. et al. pROC: an open-source package for R and S+ to analyze and compare ROC curves. BMC Bioinformatics 12, 77 , https://doi.org/10.1186/1471-2105-12-77 (2011).

18. DeLong, E. R., DeLong, D. M. \& Clarke-Pearson, D. L. Comparing the areas under two or more correlated receiver operating characteristic curves: a nonparametric approach. Biometrics 44, 837-845 (1988).

19. Caraguel, C. G. \& Vanderstichel, R. The two-step Fagan's nomogram: ad hoc interpretation of a diagnostic test result without calculation. Evid Based Med 18, 125-128, https://doi.org/10.1136/eb-2013-101243 (2013).

20. Ray, P., Le Manach, Y., Riou, B. \& Houle, T. T. Statistical evaluation of a biomarker. Anesthesiology 112, 1023-1040, https://doi. org/10.1097/ALN.0b013e3181d47604 (2010).

21. Berek, K. et al. Early determination of neurological outcome after prehospital cardiopulmonary resuscitation. Stroke; a journal of cerebral circulation 26, 543-549 (1995).

22. Oddo, M. et al. Early predictors of outcome in comatose survivors of ventricular fibrillation and non-ventricular fibrillation cardiac arrest treated with hypothermia: a prospective study. Critical care medicine 36, 2296-2301, https://doi.org/10.1097/ CCM.0b013e3181802599 (2008).

23. Michenfelder, J. D. \& Theye, R. A. The effects of anesthesia and hypothermia on canine cerebral ATP and lactate during anoxia produced by decapitation. Anesthesiology 33, 430-439 (1970).

24. Lipton, P. Ischemic cell death in brain neurons. Physiol Rev 79, 1431-1568, https://doi.org/10.1152/physrev.1999.79.4.1431 (1999).

25. Nunes, J. C. et al. Intraoperative and anesthesia-related cardiac arrest and its mortality in older patients: a 15-year survey in a tertiary teaching hospital. PloS one 9, e104041, https://doi.org/10.1371/journal.pone.0104041 (2014).

26. Goswami, S., Brady, J. E., Jordan, D. A. \& Li, G. Intraoperative cardiac arrests in adults undergoing noncardiac surgery: incidence, risk factors, and survival outcome. Anesthesiology 117, 1018-1026, https://doi.org/10.1097/ALN.0b013e31827005e9 (2012).

27. Sebbag, I. et al. Frequency of intraoperative cardiac arrest and medium-term survival. Sao Paulo medical journal = Revista paulista de medicina 131, 309-314, https://doi.org/10.1590/1516-3180.2013.1315507 (2013).

28. Sprung, J. et al. Predictors of survival following cardiac arrest in patients undergoing noncardiac surgery: a study of 518,294 patients at a tertiary referral center. Anesthesiology 99, 259-269 (2003).

29. Mullie, A. et al. Predictive value of Glasgow coma score for awakening after out-of-hospital cardiac arrest. Cerebral Resuscitation Study Group of the Belgian Society for Intensive Care. Lancet 1, 137-140 (1988).

30. Schefold, J. C., Storm, C., Kruger, A., Ploner, C. J. \& Hasper, D. The Glasgow Coma Score is a predictor of good outcome in cardiac arrest patients treated with therapeutic hypothermia. Resuscitation 80, 658-661, https://doi.org/10.1016/j.resuscitation.2009.03.006 (2009).

31. Puttgen, H. A. \& Geocadin, R. Predicting neurological outcome following cardiac arrest. J Neurol Sci 261, 108-117, https://doi. org/10.1016/j.jns.2007.04.041 (2007).

32. Gold, B. et al. Awakening after cardiac arrest and post resuscitation hypothermia: are we pulling the plug too early? Resuscitation $\mathbf{8 5}$, 211-214, https://doi.org/10.1016/j.resuscitation.2013.10.030 (2014).

33. Hess, J. R. et al. The coagulopathy of trauma: a review of mechanisms. The Journal of trauma $65,748-754$, https://doi.org/10.1097/ TA.0b013e3181877a9c (2008).

34. Brohi, K. et al. Acute coagulopathy of trauma: hypoperfusion induces systemic anticoagulation and hyperfibrinolysis. The Journal of trauma 64, 1211-1217, discussion 1217, https://doi.org/10.1097/TA.0b013e318169cd3c (2008).

35. Niles, S. E. et al. Increased mortality associated with the early coagulopathy of trauma in combat casualties. J Trauma 64, 1459-1463, discussion 1463-1455, https://doi.org/10.1097/TA.0b013e318174e8bc (2008).

36. Bainbridge, D., Martin, J., Arango, M. \& Cheng, D. Perioperative and anaesthetic-related mortality in developed and developing countries: a systematic review and meta-analysis. Lancet 380, 1075-1081, https://doi.org/10.1016/S0140-6736(12)60990-8 (2012). 
37. Braz, L. G. et al. Perioperative cardiac arrest: a study of 53,718 anaesthetics over $9 \mathrm{yr}$ from a Brazilian teaching hospital. British journal of anaesthesia 96, 569-575, https://doi.org/10.1093/bja/ael065 (2006).

38. Drennan, I. R. et al. A comparison of the universal TOR Guideline to the absence of prehospital ROSC and duration of resuscitation in predicting futility from out-of-hospital cardiac arrest. Resuscitation 111, 96-102, https://doi.org/10.1016/j. resuscitation.2016.11.021 (2017).

\section{Acknowledgements}

The authors are thankful for the help from Ilana Sebbag, M.D. (Western University, London, ON, Canada), Gustavo Aranha (Discipline of Anaesthesiology (LIM-08), Central Institute of Clinics Hospital, Sao Paulo, Brazil) and Maria Margaritta C. Gonzalez for organizing the database. The funding for this study was institutional.

\section{Author contributions}

Matheus F. Vane helped on the design of the work, acquisition, analysis, interpretation of data and drafted the work. Maria J. C. Carmona helped design of the work, drafted the work and final review. Sergio M. Pereira helped on the acquisition, analysis, interpretation of data and drafted the work. Karl B. Kern helped on the interpretation of data and final review. Sérgio Timerman helped on the interpretation of data and final review. Guilherme Perez helped on the acquisition and analysis of data. Luiz Antonio Vane helped on the interpretation of data and final review. Denise Aya Otsuki helped on the final review. José O. C. Auler Jr helped on the design of the work, drafted the work and final review. All authors have approved the submitted version AND agree to be personally accountable for the author's own contributions and to ensure that questions related to the accuracy or integrity of any part of the work, even ones in which the author was not personally involved, are appropriately investigated, resolved, and the resolution documented in the literature.

\section{Competing interests}

The authors declare no competing interests.

\section{Additional information}

Supplementary information is available for this paper at https://doi.org/10.1038/s41598-019-51557-3.

Correspondence and requests for materials should be addressed to M.F.V.

Reprints and permissions information is available at www.nature.com/reprints.

Publisher's note Springer Nature remains neutral with regard to jurisdictional claims in published maps and institutional affiliations.

(c) (i) Open Access This article is licensed under a Creative Commons Attribution 4.0 International License, which permits use, sharing, adaptation, distribution and reproduction in any medium or format, as long as you give appropriate credit to the original author(s) and the source, provide a link to the Creative Commons license, and indicate if changes were made. The images or other third party material in this article are included in the article's Creative Commons license, unless indicated otherwise in a credit line to the material. If material is not included in the article's Creative Commons license and your intended use is not permitted by statutory regulation or exceeds the permitted use, you will need to obtain permission directly from the copyright holder. To view a copy of this license, visit http://creativecommons.org/licenses/by/4.0/.

(c) The Author(s) 2019 